Article

\title{
Diospyrin Modulates Inflammation in Poly I:C-Induced Macrophages via ER Stress-Induced Calcium-CHOP Pathway
}

\author{
Hyun-Ju Kim ${ }^{1}$, Inamullah Khan ${ }^{2}$, Adnan Shahidullah ${ }^{2}$, Syed Muhammad Ashhad Halimi ${ }^{2}$, \\ Abdur Rauf ${ }^{3}{ }^{\mathbb{D}}$, Ji-Young Lee ${ }^{1}$, Young-Jin Kim ${ }^{1}$, Bong-Youn Kim ${ }^{1}$ and Wansu Park ${ }^{1, *}$ \\ 1 Department of Pathology, College of Korean Medicine, Gachon University, Seong-nam 13120, Korea; \\ eternity0304@daum.net (H.-J.K.); oxygen1119@naver.com (J.-Y.L.); godsentry@naver.com (Y.-J.K.); \\ famous008@daum.net (B.-Y.K.) \\ 2 Department of Pharmacy, University of Peshawar, Peshawar 25120, Pakistan; \\ inam_marwat333@yahoo.com (I.K.); adnansuk1@gmail.com (A.S.); ashhad92@gmail.com (S.M.A.H.) \\ 3 Department of Chemistry, University of Swabi, Anbar 23561, KPK, Pakistan; mashaljcs@yahoo.com \\ * Correspondence: pws98@gachon.ac.kr; Tel.: +82-31-750-8821
}

Received: 29 July 2020; Accepted: 25 August 2020; Published: 27 August 2020

\begin{abstract}
Diospyrin, plant-derived bisnaphthoquinonoid, is known to have anticancer activity. However, pharmacological activity of diospyrin on viral infection is not well known. We investigated effects of diospyrin on macrophages induced by polyinosinic-polycytidylic acid (poly I:C), a mimic of double-stranded viral RNA. Various cytokines, intracellular calcium, nitric oxide (NO), phosphorylated p38 MAPK, and phosphorylated ERK1/2 as well as mRNA expressions of transcription factors were evaluated. Diospyrin significantly reduced NO production, granulocyte-macrophage colony-stimulating factor production, and intracellular calcium release in poly I:C-induced RAW 264.7. The phosphorylation of p38 MAPK and ERK1/2 was also significantly suppressed. Additionally, diospyrin inhibited mRNA levels of nitric oxide synthase 2, C/EBP homologous protein (CHOP), calcium/calmodulin dependent protein kinase II alpha, signal transducers and activators of transcription 1 (STAT1), STAT3, STAT4, Janus kinase 2, first apoptosis signal receptor, c-Jun, and c-Fos in poly I:C-induced RAW 264.7. Taken together, this study represents that diospyrin might have the inhibitory activity against viral inflammation such as excessive production of inflammatory mediators in poly I:C-induced RAW 264.7 via ER stress-induced calcium-CHOP pathway.
\end{abstract}

Keywords: diospyrin; poly I:C; viral infection; p38 MAPK; ERK1/2; CHOP; STAT; ER stress; calcium; cytokine

\section{Introduction}

Innate immune activity is thought to be essential for overcoming infectious diseases [1]. Gilroy reported that immune reaction and inflammatory activity are important against infection [2]. Recently, Nahrendorf and Swirski reported that when stimuli persist and inflammation is not resolved, monocytes might cause a chronic inflammation [3]. Then, it is reasonable that the regulation of inflammatory responses is becoming more meaningful [4].

Macrophages are important in immunity. Zong et al. reported that various inflammatory diseases are related with a complex reaction generated by macrophages [5]. In inflammatory processes, macrophages and monocytes not only produce cytokines and nitric oxide (NO) but also release intracellular calcium.

Cho et al. reported that viral infection can activate immune responses and trigger inflammatory diseases [6]. Alexopoulou et al. reported that double-stranded RNA (dsRNA) induces macrophages [7]. 
Diospyrin (Figure 1), the plant-derived bisnaphthoquinonoid, is known to have anti-leishmanial effect [8]. In the previous report, we already reported the anti-inflammatory activity of diospyrin on RAW 264.7 stimulated by lipopolysaccharide (LPS) [9]. However, the activity of diospyrin on viral inflammation is not yet reported.<smiles>Cc1cc(O)c2c(c1)C(=O)C(c1c(C)cc3c(c1O)C(=O)C=CC3=O)=CC2=O</smiles>

Figure 1. Chemical structure of diospyrin.

In this experiment, we investigated inhibitory effects of diospyrin on RAW 264.7 induced by polyinosinic-polycytidylic acid (poly I:C), a mimic of double-stranded viral RNA. Diospyrin significantly reduced productions of GM-CSF and NO as well as calcium release in RAW 264.7 induced with poly I:C. The phosphorylation of p38 MAPK and ERK1/2 was also significantly suppressed. The mRNA expressions of nitric oxide synthase 2 (NOS2), C/EBP homologous protein (CHOP), calcium/calmodulin dependent protein kinase II alpha (Camk2a), signal transducers and activators of transcription 1 (STAT1), STAT3, STAT4, Janus kinase 2 (Jak2), first apoptosis signal receptor (Fas), c-Jun, and c-Fos were reduced. Data means diospyrin might have the inhibitory activity against viral inflammation such as excessive production of inflammatory mediators in dsRNA-stimulated macrophages via ER stress-induced calcium-CHOP pathway.

\section{Materials and Methods}

\subsection{Materials}

Dulbecco's modified Eagle's medium (DMEM), other cell culture reagents, and MILLIPLEX MAP Mouse Cytokine/Chemokine assay kits were obtained from Millipore (Billerica, MA, USA). Indomethacin, baicalein, chrysin, and poly I:C were obtained from Sigma-Aldrich (St. Louis, MO, USA). Diospyrin was isolated from Diospyros lotus by Dr. Inamullah Khan. Phospho-ERK1/2 Antibody (Thr202, Tyr204) (eBioscience 12-9109-42), Phospho-p38 MAPK Antibody (T180/Y182) (eBioscience 17-9078-42), Mouse IgG1 kappa Isotype Control (eBioscience 12-4714-81), and Mouse IgG2b kappa Isotype Control (eBioscience 12-4732-81) were from Life Technologies Corporation (Carlsbad, CA, USA).

\subsection{Cell Culture}

RAW 264.7 was purchased from Korea Cell Line Bank (Seoul, Korea). In the previous study [9], we reported that diospyrin did not show any cytotoxicity up to a concentration of $10 \mu \mathrm{M}$, which was chosen for subsequent experiments.

\subsection{NO Production}

RAW 264.7 was seeded in a 96-well plate $\left(1 \times 10^{4}\right.$ cells/well $)$ and treated with diospyrin and poly I:C for $24 \mathrm{~h}$. After treatment, supernatants were collected, and NO content was measured using the modified Griess reagent assay kit (Millipore) $[9,10]$. 


\subsection{Calcium Release}

RAW 264.7 was seeded in a 96-well plate $\left(1 \times 10^{5}\right.$ cells/well $)$ and treated with diospyrin and poly $\mathrm{I}: \mathrm{C}$ for $18 \mathrm{~h}$. Then, calcium release was measured using Fluo-4 NW Calcium Assay Kits (Thermo Fisher Scientific, Waltham, MA, USA) by a spectrofluorometer (Dynex, West Sussex, UK) at $485 \mathrm{~nm}$ (excitation) and $535 \mathrm{~nm}$ (emission) [11-13]

\subsection{Cytokines Production}

RAW 264.7 was seeded in a 96-well plate $\left(1 \times 10^{4}\right.$ cells/well $)$ and treated with diospyrin and poly I:C. After $24 \mathrm{~h}$ treatment, the production of cytokines was measured using MILLIPLEX MAP Mouse Cytokine/Chemokine assay kits and Bio-Plex 200 suspension array system (Bio-Rad) [9-13].

\subsection{Quantitative Polymerase Chain Reaction}

RAW 264.7 was treated with diospyrin and poly I:C for $18 \mathrm{~h}$ in a six-well plate $\left(1 \times 10^{6} \mathrm{cells} / \mathrm{well}\right)$. After $18 \mathrm{~h}$ treatment, RNA quantity of each well was measured using NucleoSpin RNA kit (Macherey-Nagel, Duren, Germany) and Experion RNA StdSens Analysis kit (Bio-Rad) with Experion Automatic Electrophoresis System (Bio-Rad). Each cDNA was produced using iScript cDNA Synthesis kit (Bio-Rad). Then, gene expressions were measured using quantitative polymerase chain reaction with iQ SYBR Green Supermix (Bio-Rad) [14,15]. The target genes are listed in Table 1. The $\beta$-actin was used as a housekeeping gene.

Table 1. Primers used for quantitative PCR.

\begin{tabular}{|c|c|c|}
\hline Name $^{1}$ & Forward Primer $\left(5^{\prime}-3^{\prime}\right)$ & Reverse Primer $\left(5^{\prime}-3^{\prime}\right)$ \\
\hline NOS2 & TGGAGGTTCTGGATGAGAGC & AATGTCCAGGAAGTAGGTGAGG \\
\hline $\mathrm{CHOP}$ & CCACCACACCTGAAAGCAG & TCCTCATACCAGGCTTCCA \\
\hline Camk2a & AGCCATCCTCACCACTAT & ATTCCTTCACGCCATCATT \\
\hline STAT1 & TGAGATGTCCCGGATAGTGG & CGCCAGAGAGAAATTCGTGT \\
\hline STAT3 & GTCTGCAGAGT TCAAGCACCT & TCCTCAGTCACGATCAAGGAG \\
\hline STAT4 & TTCAGAGCAGCTCAACATGC & GGTGAGGTGACCATCATTGTAG-3 \\
\hline Jak2 & TTGGTTTTGAATTATGGTGTCTGT & TCCAAATTTTACAAATTCTTGAACC \\
\hline Fas & CGCTGTTTTCCCTTGCTG & CCTTGAGTATGAACTCTTAACTGTGAG \\
\hline c-Jun & ACTGGGTTGCGACCTGAC & CAATAGGCCGCTGCTCTC \\
\hline$c-F o s$ & AGAGCGGGAATGGTGAAGA & TCTTCCTCTTCAGGAGATAGCTG \\
\hline$\beta$-Actin & CTAAGGCCAACCGTGAAAAG & ACCAGAGGCATACAGGGACA \\
\hline
\end{tabular}

1. Primer names; nitric oxide synthase 2 (NOS2), C/EBP homologous protein (CHOP), calcium/calmodulin dependent protein kinase II alpha (Camk2a), signal transducers and activators of transcription 1 (STAT1), STAT3, STAT4, Janus kinase 2 (Jak2), first apoptosis signal receptor (Fas), c-Jun, c-Fos, and $\beta$-Actin.

\subsection{Flow Cytometry Assay}

RAW 264.7 was seeded in a six-well plate $\left(1 \times 10^{6}\right.$ cells/well $)$ and treated with diospyrin and poly I:C for $15 \mathrm{~min}$. After incubation, cells were harvested and washed with Flow Cytometry Staining Buffer. Prior to antibody staining, cells were fixed and permeabilized using Fix Buffer I and Perm Buffer III, respectively. RAW 264.7 stained with Phospho-ERK1/2 (Thr202, Tyr204) Antibody (eBioscience 12-9109-42) and phospho-p38 MAPK (T180/Y182) Antibody (eBioscience 17-9078-42) were analyzed on the Attune NxT flow cytometer (Thermo Fisher Scientific) using Attune NxT software.

\subsection{Statistics}

Data are presented as mean $\pm \mathrm{SD}$. All data were analyzed by one-way analysis of variance test followed by Tukey's multiple comparison test using GraphPad Prism (ver. 4; GraphPad Software, San Diego, CA, USA). 


\section{Results}

\subsection{NO Production from RAW 264.7}

NO production from RAW 264.7 after $24 \mathrm{~h}$ treatment of diospyrin at concentrations of 1, 5, and $10 \mu \mathrm{M}$ were $92.02 \pm 6.15 \%, 93.52 \pm 4.44 \%$, and $93.27 \pm 4.99 \%$ of media group (Figure $2 \mathrm{~A}$ ). In the case of poly I:C stimulation, diospyrin at concentrations of 1,5 , and $10 \mu \mathrm{M}$ showed $88.58 \pm 3.24 \%$, $48.4 \pm 8.08 \%$, and $45.48 \pm 3.95 \%$ of the poly I:C alone ( $p<0.001)$ (Figure $2 \mathrm{~B}$ ).
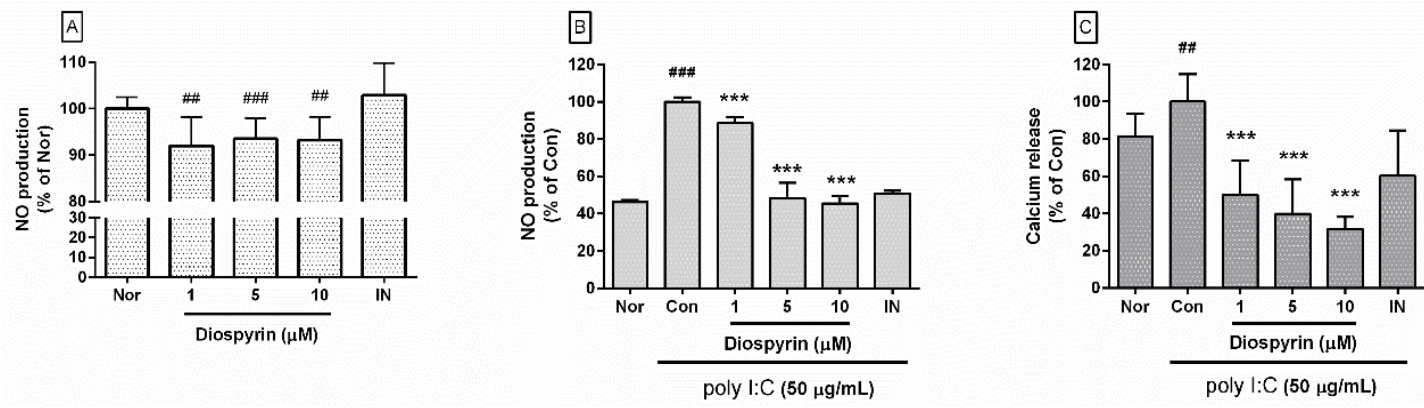

Figure 2. Effect of diospyrin on production of nitric oxide $(\mathbf{A}, \mathbf{B})$ and calcium release $(\mathbf{C})$. Values are mean \pm SD of the three independent experiments. Nor, normal group (media only); Con, control group (poly I:C alone); IN, indomethacin $(0.5 \mu \mathrm{M}) .{ }^{\# \#} p<0.01$ vs. Nor; ${ }^{\# \#} p<0.001$ vs. Nor; ${ }^{* * *} p<0.001$ vs. Con.

\subsection{Calcium Release in RAW 264.7}

Calcium release with diospyrin at concentrations of 1,5 , and $10 \mu \mathrm{M}$ were $50.07 \pm 18.52 \%$, $39.82 \pm 18.39 \%$, and $31.61 \pm 6.69 \%$ of the poly I:C alone $(p<0.001)$ (Figure $2 \mathrm{C}$ ).

\subsection{Cytokine Production from RAW 264.7}

Diospyrin significantly reduced GM-CSF production in RAW 264.7 stimulated by poly I:C. Concretely, GM-CSF production from RAW 264.7 with diospyrin at concentrations of $0.1,1$, and $5 \mu \mathrm{M}$ were $49.46 \pm 6.26 \%, 38.45 \pm 6.45 \%$, and $5.37 \pm 0.58 \%$ of the poly I:C alone; MCP- 1 were $70.66 \pm 4.79 \%$, $55.11 \pm 9.17 \%$, and $89.39 \pm 8.72 \%$; IL-6 were $99.15 \pm 1.98 \%, 96.72 \pm 1.98 \%$, and $68.5 \pm 5.13 \%$; LIF were $86.75 \pm 6.77 \%, 85.79 \pm 6.03 \%$, and $73.29 \pm 2.74 \%$; VEGF were $97.94 \pm 11.18 \%, 96.66 \pm 7.7 \%$, and $58.73 \pm 0.48 \%$; IL-15 were $80 \pm 6.44 \%, 74.09 \pm 5.51 \%$, and $60.91 \pm 1.56 \%$; Eotaxin were $84.62 \pm 9.24 \%$, $84.16 \pm 11.11 \%$, and $85.97 \pm 7.84 \%$; IP-10 were $84.62 \pm 9.24 \%, 84.16 \pm 11.11 \%$, and $85.97 \pm 7.84 \%$ (Figure 3).

\section{4. mRNA Expression of NOS2, CHOP, Camk2a, STAT1, STAT3, STAT4, Jak2, Fas, c-Jun, and c-Fos}

Diospyrin inhibited expressions of NOS2, CHOP, Camk2a, STAT1, STAT3, STAT4, Jak2, Fas, c-Jun, and $c$-Fos in RAW 264.7 stimulated by poly I:C $(p<0.05)$ (Figure 4). Concretely, NOS2 expression in RAW 264.7 treated with diospyrin at concentrations of 1,5 , and $10 \mu \mathrm{M}$ were $18.9 \pm 1.33 \%, 0.05 \pm 0.01 \%$, and $38.72 \pm 4.72 \%$ of the poly I:C alone; $\mathrm{CHOP}$ were $31.05 \pm 2.64 \%, 17.47 \pm 1.87 \%$, and $21.43 \pm 1.69 \%$; Camk2a were $7.64 \pm 2.28 \%, 8.93 \pm 0.43 \%$, and $9.44 \pm 0.69 \%$; STAT1 were $13.58 \pm 4.69 \%, 24.54 \pm 8.59 \%$, and $21.68 \pm 2.62 \%$; STAT3 were $12.01 \pm 1.36 \%, 22.9 \pm 7.41 \%$, and $16.37 \pm 6.56 \%$; STAT4 were $8.89 \pm 1.35 \%$, $2.31 \pm 0.82 \%$, and $37.79 \pm 11.83 \%$; Jak2 were $11.97 \pm 3.03 \%, 15.41 \pm 3.99 \%$, and $27.1 \pm 7.84 \%$; Fas were $14.39 \pm 5.29 \%, 10.98 \pm 1.26 \%$, and $21.98 \pm 4.75 \%$; c-Jun were $13.99 \pm 4.17 \%, 16.82 \pm 11.55 \%$, and $17.71 \pm 5.93 \%$; c-Fos were $5.04 \pm 1.94 \%, 14.15 \pm 2 \%$, and $26.54 \pm 2.44 \%$. 

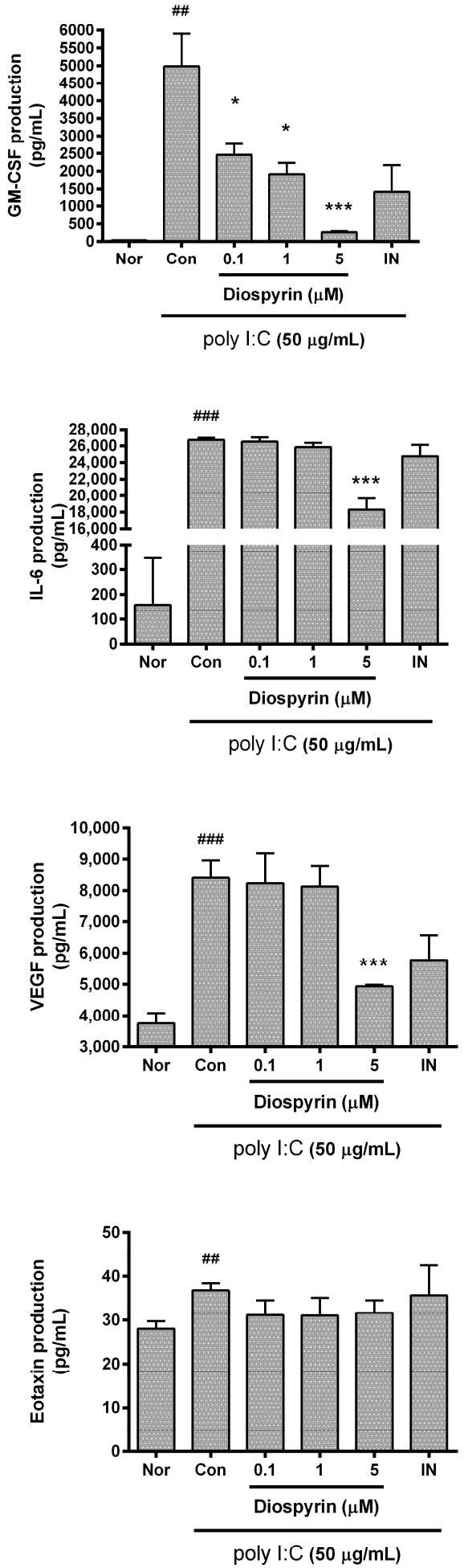
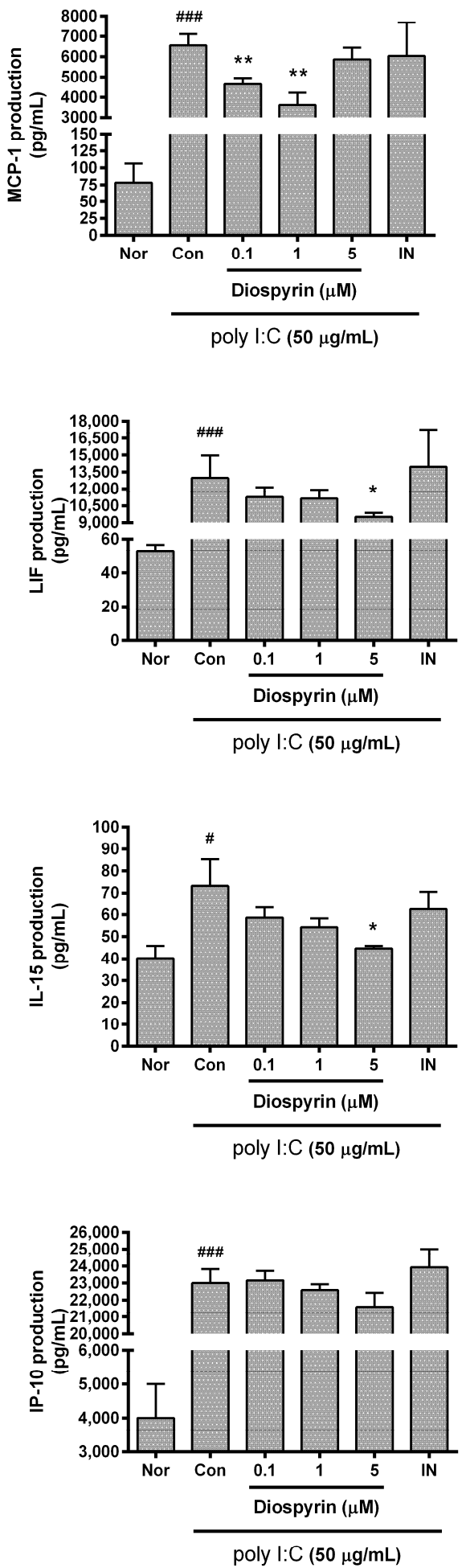

Figure 3. Effect of diospyrin on cytokine production from RAW 264.7. Values are the mean \pm SD of the three independent experiments. Nor, media alone; IN, indomethacin $(0.5 \mu \mathrm{M}) .{ }^{\#} p<0.05$ vs. Nor; ${ }^{\# \#} p<0.01$ vs. Nor; ${ }^{\# \#} p<0.001$ vs. Nor; ${ }^{*} p<0.05$ vs. Con; ${ }^{* *} p<0.01$ vs. Con; ${ }^{* * *} p<0.001$ vs. Con. 

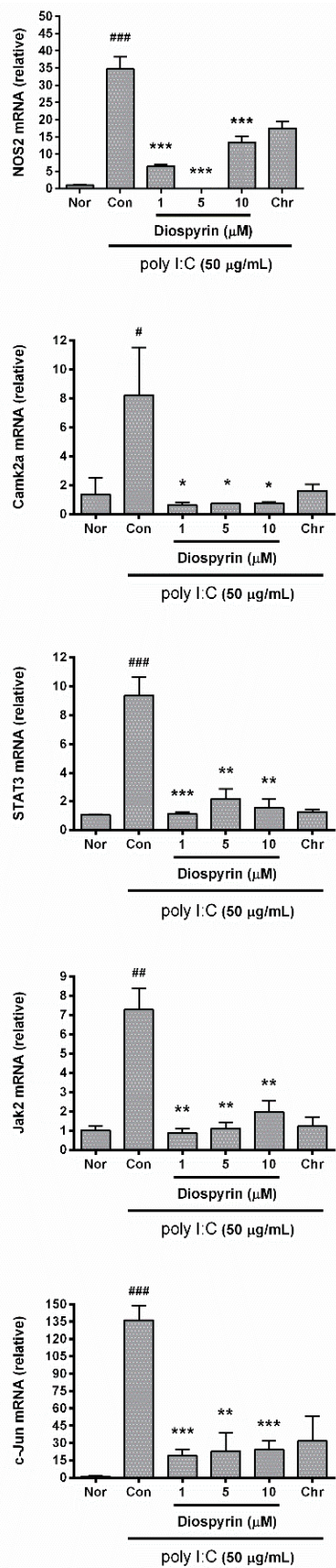
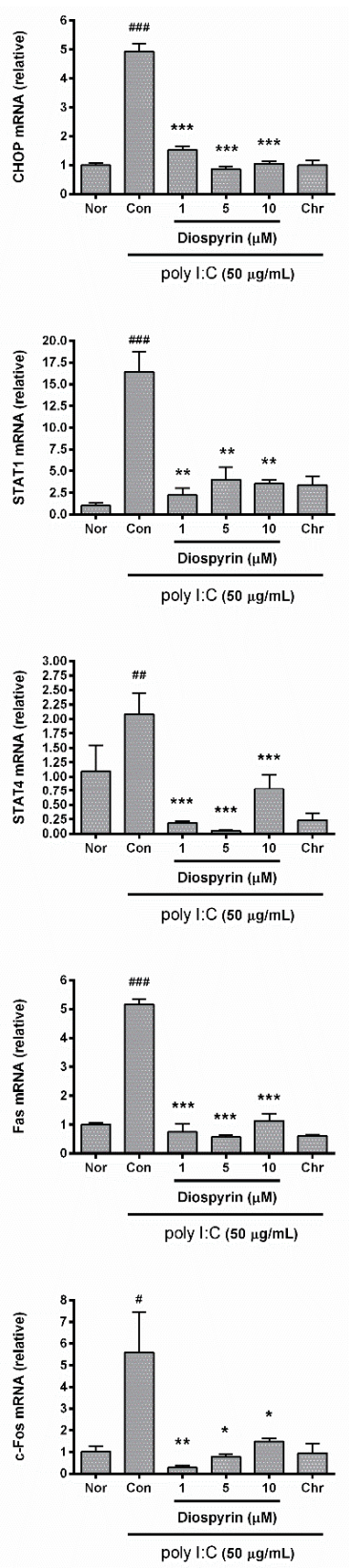

Figure 4. Expressions of NOS2, CHOP, Camk2a, STAT1, STAT3, STAT4, Jak2, Fas, c-Jun, and c-Fos mRNA in RAW 264.7. mRNA expressions were normalized to $\beta$-actin. Values are the mean \pm SD of the three independent experiments. Nor, media alone; Chr, Chrysin $(10 \mu \mathrm{M}) .{ }^{\#} p<0.05$ vs. Nor; ${ }^{\# \#} p<0.01$ vs. Nor; ${ }^{\# \# \#} p<0.001$ vs. Nor; ${ }^{*} p<0.05$ vs. Con; ${ }^{* *} p<0.01$ vs. Con; ${ }^{* * *} p<0.001$ vs. Con.

\subsection{Phosphorylation of $p 38$ MAPK and ERK1/2 in RAW 264.7}

The phosphorylation of p38 MAPK and ERK $1 / 2$ was inhibited by diospyrin significantly (Figure 5). To be concrete, p38 MAPK phosphorylation in RAW 264.7 with diospyrin at concentrations of 1, 5, and $10 \mu \mathrm{M}$ were $91.38 \pm 1.64 \%, 48.69 \pm 1.58 \%$, and $41.73 \pm 0.46 \%$ of the poly I:C alone; ERK $1 / 2$ were $91.23 \pm 3.59 \%, 53.79 \pm 1.74 \%$, and $31.64 \pm 0.34 \%$. 


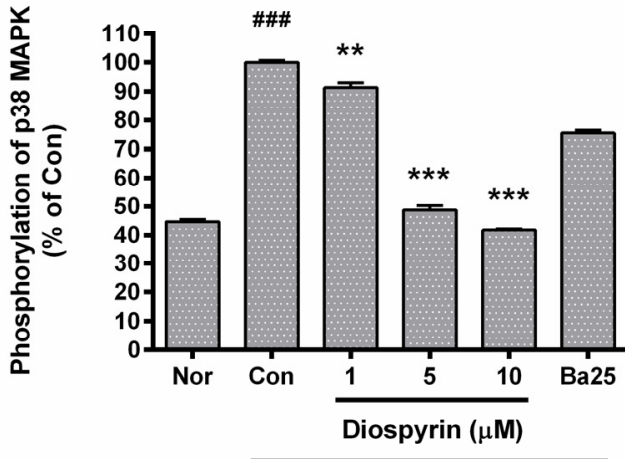

poly I:C $(50 \mu \mathrm{g} / \mathrm{mL})$

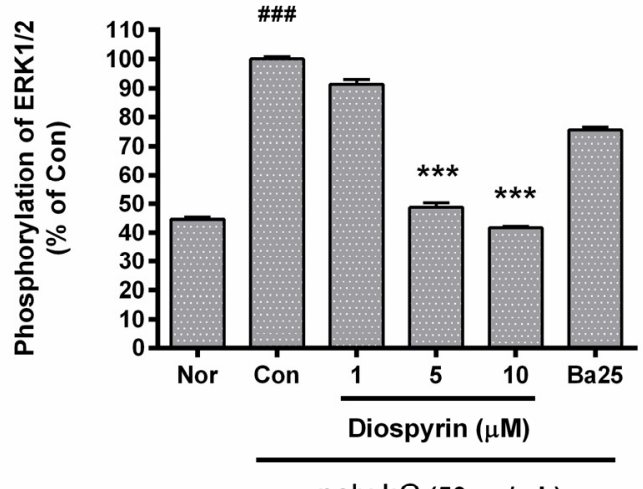

poly I:C $(50 \mu \mathrm{g} / \mathrm{mL})$

Figure 5. The phosphorylation of p38 MAPK and ERK $1 / 2$ in RAW 264.7. Values are the mean \pm SD of the three independent experiments. Nor, media alone; Ba25, Baicalein $(25 \mu \mathrm{M}) .{ }^{\# \#} p<0.001$ vs. Nor. ** $p<0.01$ vs. Con; ${ }^{* * *} p<0.001$ vs. Con.

\section{Discussion}

Diospyrin, the medicinal plant (i.e., species of Diospyros such as Diospyros lotus and Diospyros montana)-derived bisnaphthoquinonoid, is known to suppress cancer [16], tuberculosis [17], and leishmaniasis $[18,19]$. In detail, Bailly reported in 2000 that diospyrin exerts the activity of a topoisomerase I suppressor, resulting in anti-tumor effect [16]. Lall et al. reported in 2005 that diospyrin exerted the inhibitory activity against Mycobacterium tuberculosis [20]. In 2013, Hazra et al. reported that diospyrin represented the anti-leishmanial activity [19]. But effects of diospyrin on viral inflammation have been rarely reported so far.

Although the innate immunity is essential for overcoming hazardous infections, the uncontrolled immuno-inflammatory reaction such as cytokine storm also might be fatal for human life. Thus, the resolution of excessive inflammation is being required continuously because there is no pertinent therapeutics against the newly emerged pandemic viral infection (such as Coronavirus Disease-19), which sometimes provokes cytokine storm.

Karpuzoglu and Ahmed reported that excessive NO production might be concerned with inflammatory diseases such as inflammatory autoimmune diseases [21]. Moreover, it is well reported that excessive production of NO contributes to septic shock [22]. Cooper et al. reported that viral infections might cause airway inflammation and increase the production of various cytokines excessively [23]. Interestingly, respiratory tract viral infections such as Influenza A and Parainfluenza virus were reported to show higher levels of GM-CSF, IL-17A, and IL-22 [24]. In this year, Crisci et al. reported that cytokines such as GM-CSF, VEGF, MCP-1, IL-6, and LIF were increased in severe patients with COVID-19 [25]. It is reasonable that excessive production of cytokines becomes a major target for relieving inflammatory illnesses [26]. In this study, we tried to find a material able to inhibit hyper-production of cytokines in macrophages induced with virus-like particles. During viral infection, dsRNA is produced in host cells and brings about viral inflammatory reaction in macrophages producing NO, ILs, TNF- $\alpha$, and other cytokines [27]. Then, multiplex cytokine assay is regarded to be effective for checking anti-inflammatory activity of drug candidates [28-32]. For example, Kim et al. reported that baicalein showed inhibitory effects on productions of various cytokines in poly I:C-induced RAW 264.7 [14]. Meanwhile, Alexopoulou et al. reported in 2001 that dsRNA recognized by mammalian Toll-like receptor 3 might provoke inflammatory response via activation of p38 MAPK and ERK1/2 [7]. However, it is not yet fully reported for effects of diospyrin on viral inflammation.

In this experiment, bio-activity of diospyrin in poly I:C-induced RAW 264.7 was evaluated using multiplex cytokine assay, flow cytometry assay, etc. Experimental data means that diospyrin reduces the production of NO and GM-CSF as well as phosphorylation of p38 MAPK and ERK1/2 in poly I:C-induced RAW 264.7. As NO is related with septic shock, diospyrin could be tested for relieving cytokine storm with viral sepsis. 
Recently, pandemic viral infection COVID-19 has produced a global threat. Interestingly, TNF- $\alpha$-converting enzyme (TACE) was reported to be involved in the cell entry of SARS-CoV [33,34]. Xiao et al. reported that SARS-CoV-2 binds angiotensin-converting enzyme 2 (ACE2) for cell entry [35]. ACE2 is known to be shed by TACE and Palau et al. suggested that TACE inhibition may be important for protecting COVID-19 [36]. Additionally, Scott et al. reported in 2011 that TACE activity is upregulated in LPS-induced human monocytes through p38 activation [37]. In this study, the authors presented TACE inhibitory potential of diospyrin predicted by structure-based virtual screening in Figure 6. However, more studies are needed to ascertain whether diospyrin exerts a meaningful effect on TACE activity.

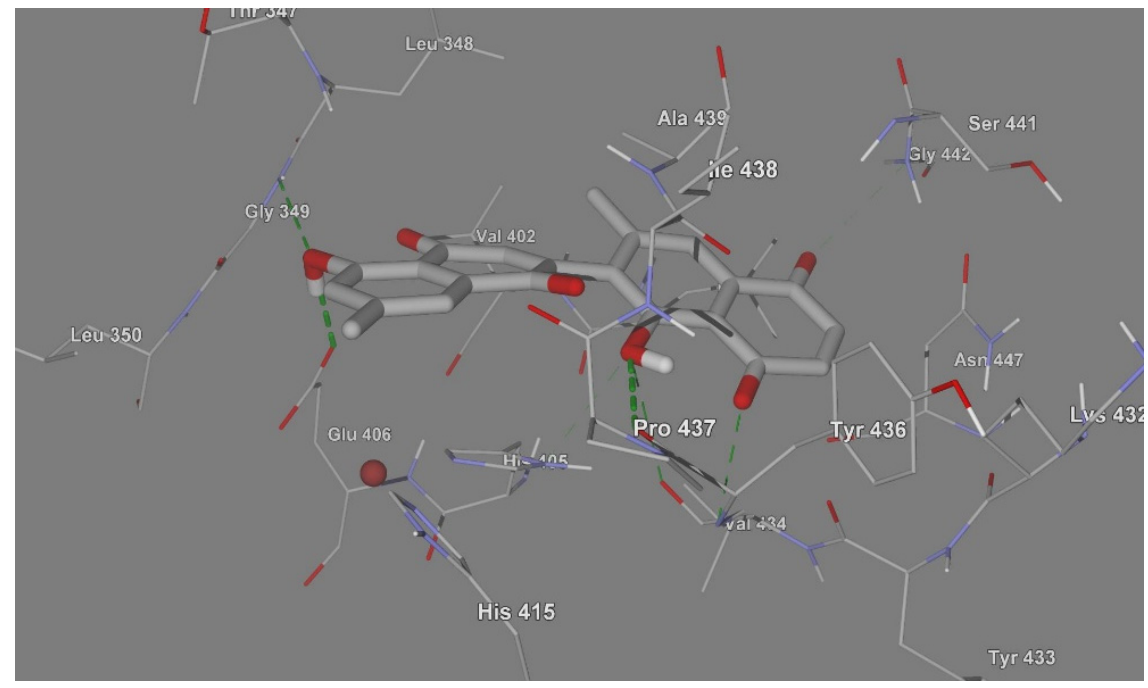

Figure 6. Predicted binding mode of lowest energy conformation of diospyrin inside the active site of TNF- $\alpha$-converting enzyme (TACE).

With an infection of microorganisms, macrophages show a distinct reaction, called pyroptosis, which is different from both apoptosis and necrosis. In pyroptosis, various inflammatory mediators are produced from infected macrophages [38]. In 2016, Broz and Dixit also reported about pyroptotic cells to produce many kinds of cytokines [39]. In 2019, Goddard et al. reported that microbial infections can stimulate macrophages [40]. However, it is not yet fully reported for virus-induced pyroptosis accompanying massive production of inflammatory mediators with the calcium signaling pathway.

With ER stress, NO is well known to increase CHOP expression with releasing calcium from ER calcium store and leads to macrophage apoptosis [41-44]. In 2009, Timmins et al. suggested in their impressive report that ER stress-induced Camk2a activation might enable macrophage apoptosis through Fas induction and/or activation of STAT1 in macrophages [43]. In 2006, Endo et al. reported that LPS causes the overexpression of CHOP, which mediates apoptosis in macrophages and ER stress [45]. Interestingly, Stout et al. reported in 2007 that a brief activation of STAT1 induces ER stress and calcium release from ER calcium store in IFN-gamma-induced airway epithelial cell death with increase of STAT1 protein level [46]. In 2008, Lim et al. reported atheromata-related macrophage apoptosis might be provoked by ER stress through a rise in cytosolic calcium [47].

In the current study, poly I:C-induced RAW 264.7 represents propyrototic ER stress with enhancing mRNA expression of NOS2, CHOP, Camk2a, STAT1, STAT3, STAT4, Jak2, Fas, c-Jun, and $c$-Fos. Additionally, diospyrin modulates calcium release and mRNA expression of NOS2, CHOP, Camk2a, STAT1, STAT3, STAT4, Jak2, Fas, c-Jun, and c-Fos in poly I:C-induced RAW 264.7. This data means diospyrin could regulate macrophage activation in viral infection via ER stress-induced calcium-CHOP pathway.

However, this study could not elucidate whether intracellular calcium level is increased through influx of extracellular calcium or ER calcium store depletion in poly I:C-induced RAW 264.7. Further 
study is needed for the exact mechanism for anti-viral activity of diospyrin and medicinal usefulness of diospyrin on viral inflammatory diseases.

\section{Conclusions}

Diospyrin inhibits excessive production of pro-inflammatory mediators such as GM-CSF and NO via ER stress-induced calcium-CHOP pathway in poly I:C-induced RAW 264.7. Further study is required to clarify pharmacological usefulness for virus-triggered hyper-inflammation such as cytokine storm syndromes from SARS-CoV-2 infection.

Author Contributions: Conceptualization, H.-J.K., I.K., and S.M.A.H.; methodology, A.R. and W.P.; formal analysis, H.-J.K. and J.-Y.L.; investigation, H.-J.K., J.-Y.L., Y.-J.K., B.-Y.K., and W.P.; resources, A.S. and A.R.; data curation, W.P.; writing — original draft preparation, W.P.; visualization W.P.; supervision, W.P.; funding acquisition, W.P. All authors have read and agreed to the published version of the manuscript.

Funding: This research was supported by the Basic Science Research Program through the National Research Foundation of Korea, funded by the Ministry of Education, Science and Technology (2017R1A2B4004933).

Conflicts of Interest: The authors declare no conflict of interest. The funders had no role in the design of the study; in the collection, analyses, or interpretation of data; in the writing of the manuscript, or in the decision to publish the results.

\section{References}

1. Goff, W.L.; Bastos, R.G.; Brown, W.C.; Johnson, W.C.; Schneider, D.A. The Bovine Spleen: Interactions among Splenic Cell Populations in the Innate Immunologic Control of Hemoparasitic Infections. Vet. Immunol. Immunopathol. 2010, 138, 1-14. [CrossRef] [PubMed]

2. Gilroy, D.W. Eicosanoids and the Endogenous Control of Acute Inflammatory Resolution. Int. J. Biochem. Cell Biol. 2010, 42, 524-528. [CrossRef] [PubMed]

3. Nahrendorf, M.; Swirski, F.K. Immunology. Neutrophil-Macrophage Communication in Inflammation and Atherosclerosis. Science 2015, 349, 237-238. [CrossRef] [PubMed]

4. Chen, H.L.; Liao, F.; Lin, T.N.; Liu, F.T. Galectins and Neuroinflammation. Adv. Neurobiol. 2014, 9, 517-542. [PubMed]

5. Zong, Y.; Sun, L.; Liu, B.; Deng, Y.S.; Zhan, D.; Chen, Y.L.; He, Y.; Liu, J.; Zhang, Z.J.; Sun, J.; et al. Resveratrol Inhibits LPS-Induced MAPKs Activation Via Activation of the Phosphatidylinositol 3-Kinase Pathway in Murine RAW 264.7 Macrophage Cells. PLoS ONE 2012, 7, e44107. [CrossRef] [PubMed]

6. Cho, Y.S.; Challa, S.; Moquin, D.; Genga, R.; Ray, T.D.; Guildford, M.; Chan, F.K. Phosphorylation-Driven Assembly of the RIP1-RIP3 Complex Regulates Programmed Necrosis and Virus-Induced Inflammation. Cell 2009, 137, 1112-1123. [CrossRef]

7. Alexopoulou, L.; Holt, A.C.; Medzhitov, R.; Flavell, R.A. Recognition of Double-Stranded RNA and Activation of NF-kappaB by Toll-Like Receptor 3. Nature 2001, 413, 732-738. [CrossRef]

8. Ray, S.; Hazra, B.; Mittra, B.; Das, A.; Majumder, H.K. Diospyrin, a Bisnaphthoquinone: A Novel Inhibitor of Type I DNA Topoisomerase of Leishmania Donovani. Mol. Pharmacol. 1998, 54, 994-999. [CrossRef]

9. Shahidullah, A.; Lee, J.-Y.; Kim, Y.-J.; Halimi, S.M.A.; Rauf, A.; Kim, H.-J.; Kim, B.-Y.; Park, W. Anti-Inflammatory Effects of Diospyrin on Lipopolysaccharide-Induced Inflammation Using RAW 264.7 Mouse Macrophages. Biomedicines 2020, 8, 11. [CrossRef]

10. Lee, J.Y.; Park, W. Anti-Inflammatory Effect of Myristicin on RAW 264.7 Macrophages Stimulated with Polyinosinic-Polycytidylic Acid. Molecules 2011, 16, 7132-7142. [CrossRef]

11. Lee, J.Y.; Park, W.; Yi, D.K. Immunostimulatory Effects of Gold Nanorod and Silica-Coated Gold Nanorod on RAW 264.7 Mouse Macrophages. Toxicol. Lett. 2012, 209, 51-57. [CrossRef] [PubMed]

12. Lee, J.Y.; Park, W. Anti-Inflammatory Effect of Wogonin on RAW 264.7 Mouse Macrophages Induced with Polyinosinic-Polycytidylic Acid. Molecules 2015, 20, 6888-6900. [CrossRef] [PubMed]

13. Kim, Y.J.; Park, W. Anti-Inflammatory Effect of Quercetin on RAW 264.7 Mouse Macrophages Induced with Polyinosinic-Polycytidylic Acid. Molecules 2016, 21, 450. [CrossRef] [PubMed]

14. Kim, Y.J.; Kim, H.J.; Lee, J.Y.; Kim, D.H.; Kang, M.S.; Park, W. Anti-Inflammatory Effect of Baicalein on Polyinosinic(-)Polycytidylic Acid-Induced RAW 264.7 Mouse Macrophages. Viruses 2018, 10, 224. [CrossRef] [PubMed] 
15. Kim, Y.J.; Lee, J.Y.; Kim, H.J.; Kim, D.H.; Lee, T.H.; Kang, M.S.; Park, W. Anti-Inflammatory Effects of Angelica Sinensis (Oliv.) Diels Water Extract on RAW 264.7 Induced with Lipopolysaccharide. Nutrients 2018, 10, 647. [CrossRef] [PubMed]

16. Bailly, C. Topoisomerase I Poisons and Suppressors as Anticancer Drugs. Curr. Med. Chem. 2000, 7, 39-58. [CrossRef] [PubMed]

17. Sundarrajan, S.; Lulu, S.; Arumugam, M. Computational Evaluation of Phytocompounds for Combating Drug Resistant Tuberculosis by Multi-Targeted Therapy. J. Mol. Model. 2015, 21, 247. [CrossRef] [PubMed]

18. Mukherjee, P.; Majee, S.B.; Ghosh, S.; Hazra, B. Apoptosis-Like Death in Leishmania Donovani Promastigotes Induced by Diospyrin and its Ethanolamine Derivative. Int. J. Antimicrob. Agents 2009, 34, 596-601. [CrossRef] [PubMed]

19. Hazra, S.; Ghosh, S.; Das Sarma, M.; Sharma, S.; Das, M.; Saudagar, P.; Prajapati, V.K.; Dubey, V.K.; Sundar, S.; Hazra, B. Evaluation of a Diospyrin Derivative as Antileishmanial Agent and Potential Modulator of Ornithine Decarboxylase of Leishmania Donovani. Exp. Parasitol. 2013, 135, 407-413. [CrossRef]

20. Lall, N.; Meyer, J.J.M.; Wang, Y.; Bapela, N.B.; van Rensburg, C.E.J.; Fourie, B.; Franzblau, S.G. Characterization of Intracellular Activity of Antitubercular Constituents the Roots of Euclea Natalensis. Pharm. Biol. 2005, 43, 353-357. [CrossRef]

21. Karpuzoglu, E.; Ahmed, S.A. Estrogen Regulation of Nitric Oxide and Inducible Nitric Oxide Synthase (iNOS) in Immune Cells: Implications for Immunity, Autoimmune Diseases, and Apoptosis. Nitric Oxide 2006, 15, 177-186. [CrossRef] [PubMed]

22. Thiemermann, C.; Vane, J. Inhibition of Nitric Oxide Synthesis Reduces the Hypotension Induced by Bacterial Lipopolysaccharides in the Rat in Vivo. Eur. J. Pharmacol. 1990, 182, 591-595. [CrossRef]

23. Cooper, P.R.; Lamb, R.; Day, N.D.; Branigan, P.J.; Kajekar, R.; San Mateo, L.; Hornby, P.J.; Panettieri, R.A., Jr. TLR3 Activation Stimulates Cytokine Secretion without Altering Agonist-Induced Human Small Airway Contraction Or Relaxation. Am. J. Physiol. Lung Cell. Mol. Physiol. 2009, 297, L530-L537. [CrossRef]

24. Antalis, E.; Spathis, A.; Kottaridi, C.; Kossyvakis, A.; Pastellas, K.; Tsakalos, K.; Mentis, A.; Kroupis, C.; Tsiodras, S. Th17 Serum Cytokines in Relation to Laboratory-Confirmed Respiratory Viral Infection: A Pilot Study. J. Med. Virol. 2019, 91, 963-971. [CrossRef] [PubMed]

25. Crisci, C.D.; Ardusso, L.R.F.; Mossuz, A.; Muller, L. A Precision Medicine Approach to SARS-CoV-2 Pandemic Management. Curr. Treat. Options Allergy 2020. [CrossRef]

26. Teijaro, J.R. Cytokine storms in infectious diseases. Semin. Immunopathol. 2017, 39, 501-503. [CrossRef] [PubMed]

27. Shaheen, Z.R.; Corbett, J.A. Macrophage Expression of Inflammatory Genes in Response to EMCV Infection. Biomolecules 2015, 5, 1938-1954. [CrossRef] [PubMed]

28. Lee, J.Y.; Kim, Y.J.; Kim, H.J.; Kim, Y.S.; Park, W. Immunostimulatory Effect of Laminarin on RAW 264.7 Mouse Macrophages. Molecules 2012, 17, 5404-5411. [CrossRef]

29. Kim, H.K.; Lee, J.Y.; Han, H.S.; Kim, Y.J.; Kim, H.J.; Kim, Y.S.; Kim, H.M.; Ko, S.G.; An, H.J.; Lee, Y.J.; et al. Immunomodulatory Effects of Liriope Platyphylla Water Extract on Lipopolysaccharide-Activated Mouse Macrophage. Nutrients 2012, 4, 1887-1897. [CrossRef]

30. Lee, J.Y.; Park, W. Anti-Inflammatory Effects of Oroxylin A on RAW 264.7 Mouse Macrophages Induced with Polyinosinic-Polycytidylic Acid. Exp. Ther. Med. 2016, 12, 151-156. [CrossRef]

31. Lee, J.Y.; Park, W. Anti-Inflammatory Effect of Chrysin on RAW 264.7 Mouse Macrophages Induced with Polyinosinic-Polycytidylic Acid. Biotechnol. Bioprocess Eng. 2015, 20, 1026-1034. [CrossRef]

32. Kim, Y.J.; Lee, J.Y.; Kim, H.J.; Kim, D.H.; Lee, T.H.; Kang, M.S.; Choi, Y.K.; Lee, H.L.; Kim, J.; An, H.J.; et al. Inhibitory Effect of Emodin on Raw 264.7 Activated with Double Stranded Rna Analogue Poly I:C. Afr. J. Tradit. Complement. Altern. Med. 2017, 14, 157-166. [CrossRef] [PubMed]

33. Haga, S.; Yamamoto, N.; Nakai-Murakami, C.; Osawa, Y.; Tokunaga, K.; Sata, T.; Yamamoto, N.; Sasazuki, T.; Ishizaka, Y. Modulation of TNF-Alpha-Converting Enzyme by the Spike Protein of SARS-CoV and ACE2 Induces TNF-Alpha Production and Facilitates Viral Entry. Proc. Natl. Acad. Sci. USA 2008, 105, 7809-7814. [CrossRef] [PubMed]

34. Heurich, A.; Hofmann-Winkler, H.; Gierer, S.; Liepold, T.; Jahn, O.; Pohlmann, S. TMPRSS2 and ADAM17 Cleave ACE2 Differentially and Only Proteolysis by TMPRSS2 Augments Entry Driven by the Severe Acute Respiratory Syndrome Coronavirus Spike Protein. J. Virol. 2014, 88, 1293-1307. [CrossRef] 
35. Xiao, L.; Sakagami, H.; Miwa, N. ACE2: The Key Molecule for Understanding the Pathophysiology of Severe and Critical Conditions of COVID-19: Demon or Angel? Viruses 2020, 12, 491. [CrossRef] [PubMed]

36. Palau, V.; Riera, M.; Soler, M.J. ADAM17 Inhibition may Exert a Protective Effect on COVID-19. Nephrol. Dial. Transplant. 2020. [CrossRef]

37. Scott, A.J.; O’Dea, K.P.; O'Callaghan, D.; Williams, L.; Dokpesi, J.O.; Tatton, L.; Handy, J.M.; Hogg, P.J.; Takata, M. Reactive Oxygen Species and p38 Mitogen-Activated Protein Kinase Mediate Tumor Necrosis Factor Alpha-Converting Enzyme (TACE/ADAM-17) Activation in Primary Human Monocytes. J. Biol. Chem. 2011, 286, 35466-35476. [CrossRef]

38. Sarhan, J.; Liu, B.C.; Muendlein, H.I.; Li, P.; Nilson, R.; Tang, A.Y.; Rongvaux, A.; Bunnell, S.C.; Shao, F.; Green, D.R.; et al. Caspase-8 Induces Cleavage of Gasdermin D to Elicit Pyroptosis during Yersinia Infection. Proc. Natl. Acad. Sci. USA 2018, 115, E10888-E10897. [CrossRef]

39. Broz, P.; Dixit, V.M. Inflammasomes: Mechanism of Assembly, Regulation and Signalling. Nat. Rev. Immunol. 2016, 16, 407-420. [CrossRef]

40. Goddard, P.J.; Sanchez-Garrido, J.; Slater, S.L.; Kalyan, M.; Ruano-Gallego, D.; Marches, O.; Fernandez, L.A.; Frankel, G.; Shenoy, A.R. Enteropathogenic Escherichia Coli Stimulates Effector-Driven Rapid Caspase-4 Activation in Human Macrophages. Cell Rep. 2019, 27, 1008-1017.e6. [CrossRef]

41. Gotoh, T.; Terada, K.; Oyadomari, S.; Mori, M. Hsp70-DnaJ Chaperone Pair Prevents Nitric Oxide- and CHOP-Induced Apoptosis by Inhibiting Translocation of Bax to Mitochondria. Cell Death Differ. 2004, 11, 390-402. [CrossRef] [PubMed]

42. Tabas, I.; Seimon, T.; Timmins, J.; Li, G.; Lim, W. Macrophage Apoptosis in Advanced Atherosclerosis. Ann. N. Y. Acad. Sci. 2009, 1173 (Suppl. 1), E40-E45. [CrossRef]

43. Timmins, J.M.; Ozcan, L.; Seimon, T.A.; Li, G.; Malagelada, C.; Backs, J.; Backs, T.; Bassel-Duby, R.; Olson, E.N.; Anderson, M.E.; et al. Calcium/calmodulin-Dependent Protein Kinase II Links ER Stress with Fas and Mitochondrial Apoptosis Pathways. J. Clin. Invest. 2009, 119, 2925-2941. [CrossRef] [PubMed]

44. Mori, M. Regulation of Nitric Oxide Synthesis and Apoptosis by Arginase and Arginine Recycling. J. Nutr. 2007, 137, 1616S-1620S. [CrossRef] [PubMed]

45. Endo, M.; Mori, M.; Akira, S.; Gotoh, T. C/EBP Homologous Protein (CHOP) is Crucial for the Induction of Caspase-11 and the Pathogenesis of Lipopolysaccharide-Induced Inflammation. J. Immunol. 2006, 176, 6245-6253. [CrossRef] [PubMed]

46. Stout, B.A.; Melendez, K.; Seagrave, J.; Holtzman, M.J.; Wilson, B.; Xiang, J.; Tesfaigzi, Y. STAT1 Activation Causes Translocation of Bax to the Endoplasmic Reticulum during the Resolution of Airway Mucous Cell Hyperplasia by IFN-Gamma. J. Immunol. 2007, 178, 8107-8116. [CrossRef] [PubMed]

47. Lim, W.S.; Timmins, J.M.; Seimon, T.A.; Sadler, A.; Kolodgie, F.D.; Virmani, R.; Tabas, I. Signal Transducer and Activator of Transcription-1 is Critical for Apoptosis in Macrophages Subjected to Endoplasmic Reticulum Stress in Vitro and in Advanced Atherosclerotic Lesions in Vivo. Circulation 2008, 117, 940-951. [CrossRef] [PubMed]

(C) 2020 by the authors. Licensee MDPI, Basel, Switzerland. This article is an open access article distributed under the terms and conditions of the Creative Commons Attribution (CC BY) license (http://creativecommons.org/licenses/by/4.0/). 